\title{
Cytogenetic and molecular analysis of the multiple sex chromosome system of Rumex acetosa
}

\author{
C. RUIZ REJÓN ${ }^{1 *}$, M. JAMILENA ${ }^{1}$, M. GARRIDO RAMOS ${ }^{1}$, J. S. PARKER ${ }^{2} \&$ \\ M. RUIZ REJÓN ${ }^{1}$ \\ ${ }^{1}$ Departmento de Genetica, Facultad de Ciencias, Universidad de Granada, 18071 Granada, Spain and ${ }^{2}$ Department of \\ Botany, School of Plant Sciences, University of Reading, Whiteknights, Reading, RG6 2AS, U.K.
}

\begin{abstract}
A repeated sequence of $180 \mathrm{bp}$ in tandem array has been isolated from the dioecious plant species Rumex acetosa which has a multiple sex chromosome system, $\mathrm{XX}$ \% $/ \mathrm{XY}_{1} \mathrm{Y}_{2}$ ठ". There are two or three thin $\mathrm{C}$-bands on the $\mathrm{X}$ while the $\mathrm{Ys}$ are almost entirely heteropycnotic and DAPI-positive but contain no C-band material. The Ys thus represent massive blocks of facultative heterochromatin. The 180 bp sequence has been localized to the $\mathrm{X}$ and both $\mathrm{Y}$ chromosomes by in situ hybridization. The molecular data support an origin of the sex-multiple from a homomorphic chromosome pair rather than from a sex chromosome/autosome translocation.
\end{abstract}

Keywords: Origin of sex multiples, plant sex chromosomes, Rumex acetosa, sex-localized repetitive sequences.

\section{Introduction}

In contrast to the sex chromosomes of animals, the sex chromosomes of dioecious flowering plants have recently been given little attention. Sex chromosomes were discovered early in angiosperms (Blackburn, 1923; Kihara \& Ono, 1923; reviewed by Westergaard, 1958 ) but analyses by modern cytological and molecular techniques have only recently been attempted. Most of these studies address the role of sex chromosomes in sex determination (Negrutiu \& Sala, 1991) but many important aspects such as the euchromatic or heterochromatic nature of plant sex chromosomes, their molecular composition and their evolution remain unknown.

Recently we have undertaken an analysis of the sex chromosome systems of dioecious plant species (Parker, 1990; Parker \& Clark, 1991) with particular reference to Rumex acetosa which shows an X/autosome dosage system of sex determination (Parker \& Clark, 1991). The sex chromosomes of this species show a multiple system $\left(q=12+\mathrm{XX}, \sigma^{*}=12+\mathrm{XY}_{1} \mathrm{Y}_{2}\right)$ which was discovered by Kihara \& Ono (1923). Subsequently this system has been found to characterize all dioecious species of Rumex subgenus Acetosa (Wilby

*Correspondence.
\& Parker, 1988b). Zuk (1969a, b, 1970a, b) used autoradiography of one of the dioecious species $(R$. thyrsiflorus) to study the replication behaviour of the sex chromosomes. He concluded that (1) the X chromosome is euchromatic and undergoes replication simultaneously with euchromatic autosomes, and (2) the two Ys are heterochromatic and late replicating; one of the Ys starts replication simultaneously with the autosomes, the other starts later. Recently, however, extensive C-banding studies have failed to reveal heterochromatic blocks on the $\mathrm{Y}$ chromosomes of four widely-different species in the group (Clark et al., 1993).

The sex chromosome system of $R$. acetosa offers a good opportunity to test the hypotheses which have been proposed to explain both the differentiation of sex chromosomes themselves and the origin of multiple sex chromosome systems. With respect to the first aspect, Muller (1918, 1932) assumed that X and Y chromosomes evolved from a pair of autosomes with the $\mathrm{Y}$ chromosome subsequently degenerating as a consequence of its permanent heterozygosity. With respect to the origin of multiple sex chromosomes, most hypotheses claim that these systems have evolved from standard $\mathrm{XX} / \mathrm{XY}$ systems by interchanges between autosomes and $\mathrm{X}$ or $\mathrm{Y}$ chromosomes (Ohno, 1967; White, 1973). These hypotheses have only 
rarely been experimentally confirmed as in the $\mathrm{X}^{1} \mathrm{X}^{2} /$ $\mathrm{X}^{1} \mathrm{X}^{2} \mathrm{Y}$ system of Drosophila miranda (Dobzhansky, 1935; Macknight, 1939; Steinemann, 1982; Steinemann \& Steinemann, 1991). In the case of $R$. acetosa, Smith (1972) proposed that this system has originated from a standard $\mathrm{XX} / \mathrm{XY}$ system by an interchange between an autosome and the $\mathrm{X}$ chromosome such that a neo-X chromosome and a monosome, designated $Y_{2}$, were formed. But this hypothesis is only based on two observations of the distantly related American species, $R$. hastatulus: (1) this species is polytypic for two systems, $\mathrm{XX} / \mathrm{XY}$ and $\mathrm{XX} / \mathrm{XY} \mathrm{Y}^{1} \mathrm{Y}^{2}$, and (2) meiotic analyses of hybrids between the races showed homology between the $\mathrm{X}$ chromosome in the $\mathrm{XX} / \mathrm{XY} \mathrm{Y}^{1} \mathrm{Y}^{2}$ system and both the $\mathrm{Y}$ and an autosome of the $\mathrm{XX} / \mathrm{XY}$ system. By analogy with $R$. hastatulus, Smith (1972) argued that the multiple sex chromosome system of $R$. acetosa originated in a similar although independent way. However, it remains possible that the sex chromosome system of $R$. acetosa originated by a different mechanism. Wilby (1987) suggested a direct one-step origin from a homomorphic system by fission and isochromosome formation to derive two large metacentric $Y$ chromosomes homologous to opposite arms of the $X$. Thus the three sex chromosomes, $X, Y_{1}$ and $Y_{2}$ would share a common ancestry.

Our cytogenetical and molecular analyses reveal the unusual nature of the $\mathrm{Y}$ chromosomes of $R$. acetosa. As they are heteropycnotic after conventional staining but negative after C-banding (Clark et al., 1993) we can consider these chromosomes euchromatic but facultatively heterochromatinized. However, they are positive after fluorochrome staining with DAPI and are also rich in at least one highly repeated DNA sequence as is normal with heterochromatin. This repeated sequence is specific to the sex chromosomes. Clark et al. (1993) recently isolated seven non-homologous classes of highly repeated sequences from the $R$. acetosa genome but none of these classes was sex-chromosome specific nor did any show enrichment of copy number on the $\mathrm{X}$ or $\mathrm{Y}$ chromosomes by in situ hybridization. All seven clones were dispersed over autosomes and sex chromosomes. We discuss these molecular observations in the light of the above hypotheses on the origin of the multiple sex-chromosome system in $R$. acetosa.

\section{Material and methods}

Seeds and leaves were collected from a population of $R$. acetosa from Sierra Nevada (Lavadero de la Reina, Granada, Spain, 1,750 m high). Seeds were germinated in petri dishes and root tips were treated in 0.05 per cent colchicine for $2 \mathrm{~h}$ and fixed in acetic acid:ethanol $(1: 3)$. Slides were prepared following the technique described by Schwarzacher et al. (1980). C-banding and fluorochrome staining (DAPI and $\mathrm{CMA}_{3}$ ) were carried out according to methods outlined by Schwarzacher et al. (1980) and Schweizer (1980), respectively.

Isolated DNA from leaves of males and females of $R$. acetosa (Dellaporta et al., 1983) was digested with different restriction enzymes, electrophoresed on a 3 per cent Nusieve agarose gel and stained with ethidium bromide. One band of about $180 \mathrm{bp}$ obtained after Eco RI digestion which was more prominent in male than in female DNA was cut from the gel and the DNA cloned in the EcoRI site of pUC19. The ligation was used to transform $E$. coli DH5 alpha competent cells and recombinant bacteria containing the repetitive fragment of interest were selected after screening with labelled DNA from the same $180 \mathrm{bp}$ band used for cloning. The clone pRa37 was then selected for further analysis. For Southern blot hybridization, DNA from male and female plants of $R$. acetosa were digested with Eco RI, HindIII and DraI, resolved in a 0.8 per cent agarose gel, and transferred to a Hybond $\mathrm{N}^{+}$ (Amersham) nylon filter (Sambrook et al., 1989). Probe labelling, hybridization and detection of hybridization sites were performed using the non-radioactive chemiluminescence method, ECL (Amersham), following manufacturer's instructions.

In situ hybridization experiments were made with biotin-labelled pRa37. Hybridization signals were detected with alkaline phosphatase-conjugated streptavidin (Simpson et al., 1988).

\section{Results}

\section{Cytogenetical analyses}

The plants of $R$. acetosa from Sierra Nevada have a chromosome complement very similar to that described by Wilby \& Parker (1986) in plants from Britain: $2 n=12+\mathrm{XX}$ in females and $2 n=12+\mathrm{XY}_{1} \mathrm{Y}_{2}$ in males (Figs 1a and 2). The $X$ is metacentric and the largest member of the complement, the Ys are acrocentric and slightly smaller than the $\mathrm{X}$. The autosomes are much smaller than the sex chromosomes, with pairs 1-5 acrocentric. The sixth autosome pair in these Spanish plants is almost metacentric. In British plants chromosome 6 is normally acrocentric (see Fig. 2 of Wilby \& Parker, 1988a) but the presence of a heterochromatic supernumerary segment on the short arm of this pair reduces the arm ratio from $1: 2.2$ to $1: 1.5$, giving a morphologically similar chromosome to that observed in this Spanish population (Fig. 3 of Wilby \& Parker, 1988a). British populations are frequently polymorphic for supernumerary segments on chromosome 6 


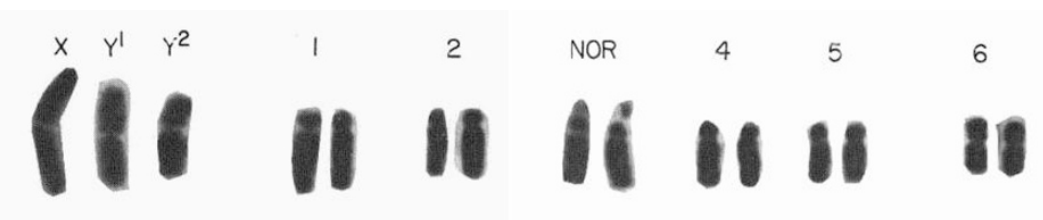

(a)

Fig. 1 Karyotypes of an $R$. acetosa male after orcein staining (a), C-banding (b), DAPI (c) and $\mathrm{CMA}_{3}$ (d) staining. For C-bands, the method of Schwarzacher et al. (1980) was used whereas the fluorochrome staining followed the procedure of Schweizer (1976).
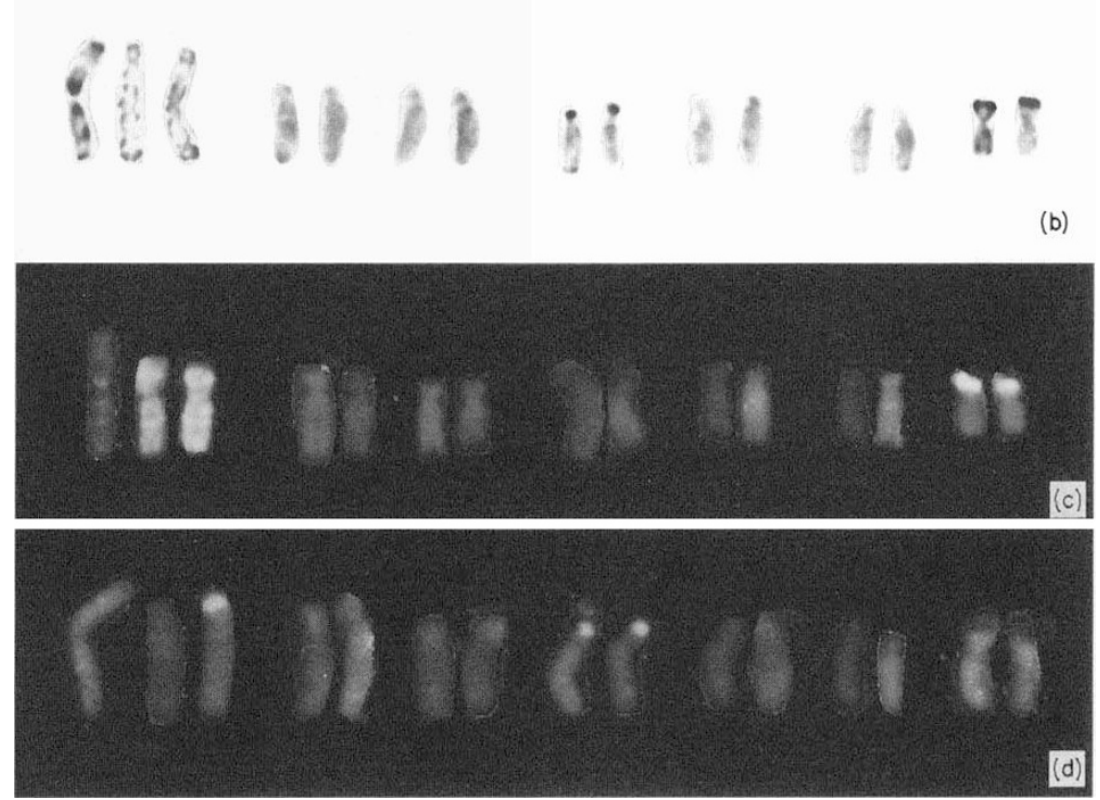

(Wilby \& Parker, 1988a) whereas the Spanish population examined is clearly fixed for the presence of the supernumerary segment. After conventional staining the Ys are heteropycnotic, appearing as chromocentres in somatic interphase nuclei (Fig. 2) and as markedly condensed elements during mitotic prophase (Wilby \& Parker, 1986).

Two large C-bands are localized on the short arm of the third NOR-bearing autosomal pair and on the short arm of the sixth pair. Polymorphic supernumerary segments also occur on the short arm of chromosome 1 and these are also $\mathrm{C}$-band positive. With respect to the sex chromosomes, two or three thin C-bands can be seen at the telomere, centromere and in an interstitial position on the $\mathrm{X}$ chromosome (Fig. 1b). The Ys are clearly C-banding negative. The C-bands of $R$. acetosa are DAPI positive (Fig. 1c) with the exception of the NOR-associated C-band of the third pair which is DAPI negative and $\mathrm{CMA}_{3}$ positive (Fig. 1d). The Ys are almost entirely DAPI positive while the $\mathrm{Y}_{2}$ chromosome has a terminal $\mathrm{CMA}_{3}$ positive band which is not present in the $\mathrm{Y}_{1}$.

\section{Molecular analyses}

To find repeated DNA sequences that were specific to (or more frequent on) $\mathrm{Y}$ chromosomes, male and female DNA was digested with different restriction enzymes and resolved in agarose gels containing ethidium bromide. In EcoRI-digested DNA, we observed some prominent bands which were more intense in males than in females (Fig. 3a), and obtained a clone from this band ( $\mathrm{pRa} 37)$.

When EcoRI-restricted DNA from males and females was resolved in agarose gel, transferred to a nylon membrane and hybridized with the labelled 180 bp insert of $\mathrm{pRa} 37$, we observed a ladder of fragments, the lengths of which are multiples of around $180 \mathrm{bp}$ (Fig. 3b). This Southern blot hybridization pattern is indicative of a tandemly-organized repeated DNA family. The fact that male DNA showed a more intense hybridization with pRa37 than female DNA (Fig. 3b), indicates that this DNA family was located in the $\mathrm{Y}$ chromosomes and in the $\mathrm{X}$ chromosome. Quantification of hybridization, such as that seen in Fig. 3b, by photodensitometry gives an estimate that the male genome 

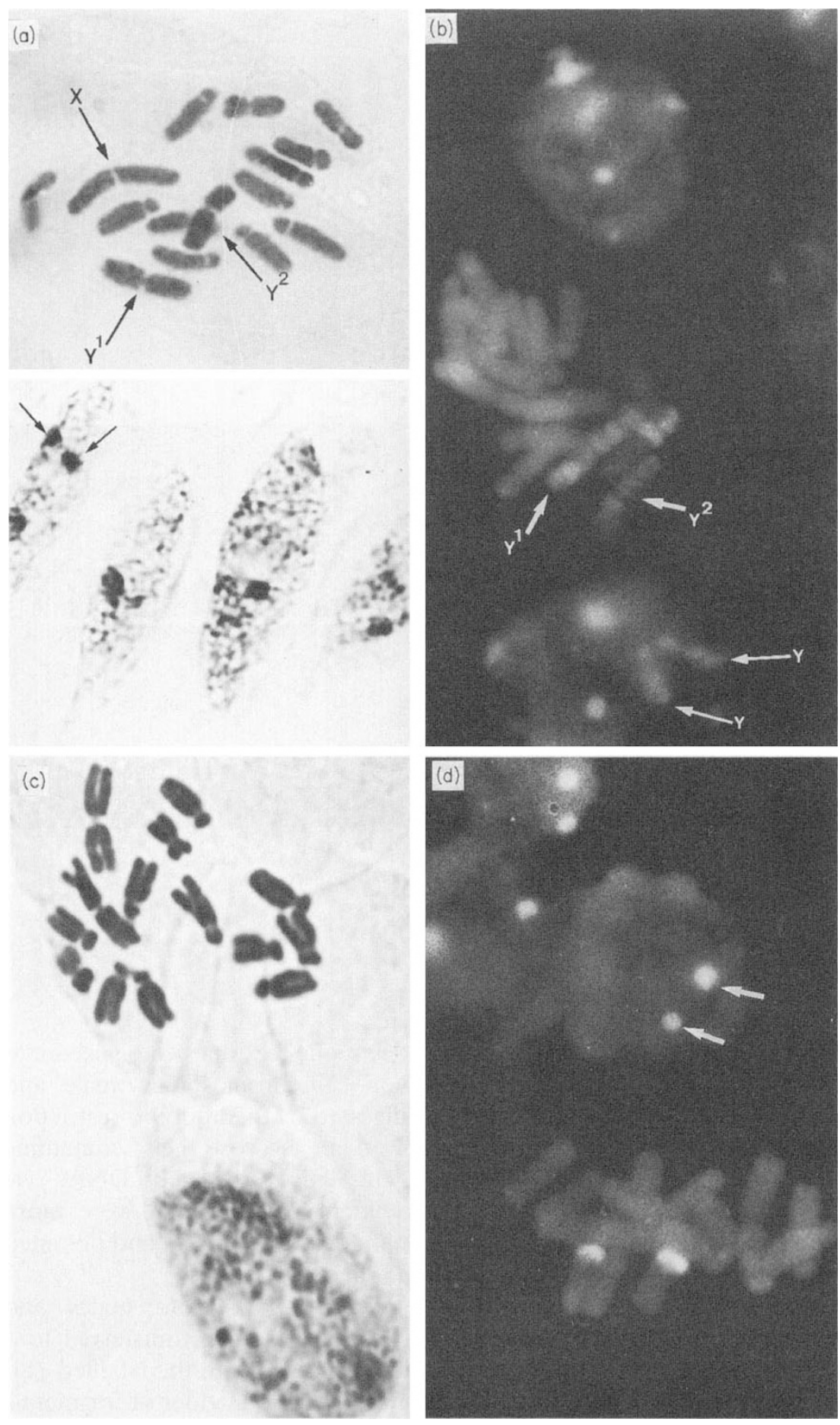

Fig. 2 Metaphase plates and interphase nuclei of orcein-stained $(a$ and $c)$ or DAPI stained $(b$ and $d)$ cells of a male ( $a$ and $b$ ) and a female ( $c$ and d) of $R$. acetosa. Note that the heteropycnotic and DAPI positive chromocentres (arrows) corresponding to the $\mathrm{Y}$ chromosomes in male cells are absent in females. In female cells, the two DAPI positive chromocentres correspond to the heterochromatic segment on the sixth chromosome pair. has about twice the amount of pRa37-related sequences as the female genome. The multimeric ladder patterns seen in almost all digests demonstrate that there is sequence variation between members of this repeated family. Furthermore, some restriction enzyme digests gave a differential hybridization pattern between females and males. Thus, in HindIII digests, male DNA showed a ladder of fragments that was absent in female DNA in which pRa37-related DNA remained mostly undigested (Fig. 3b). This observation indicates that members of this family in one or both $\mathrm{Y}$ chromosomes may be differentiated from those carried by the autosomes or $\mathrm{X}$ chromosomes. 
(a)

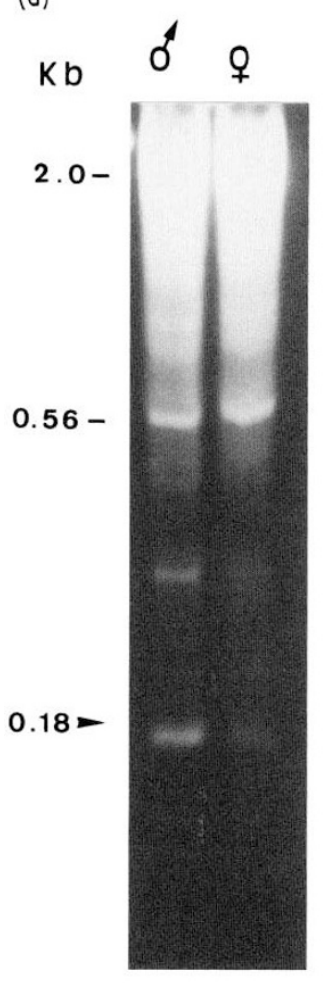

(b)

$\mathrm{Kb}$

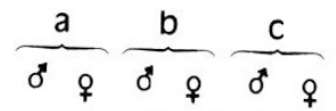

4. 4-

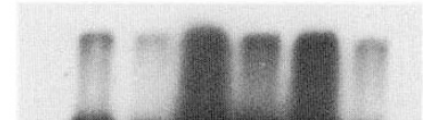

chromosomes (Marshall Graves \& Watson, 1991). However, unlike most Y chromosomes (Ohno, 1967), those of $R$. acetosa are not C-band positive. Although there are cases of heterochromatic regions that are not C-band positive (Sumner, 1990), the most likely explanation is that the $\mathrm{Y}$ chromosomes of $R$. acetosa are euchromatic in nature but facultatively heterochromatinized, similar to the $\mathrm{X}$ chromosome of female eutherian mammals. Two observations are in accordance with the euchromatic nature of these $\mathrm{Y}$ chromosomes, besides their negative C-banding pattern. Firstly, DNase-I sensitivity studies of the $R$. acetosa complement in root-tip cells (Parker \& Clark, 1991; Clark et al., 1993) failed to differentiate between autosomes, $\mathrm{X}$ or $\mathrm{Y}$ chromosomes, indicating that the $\mathrm{Y}$ chromosomes are structurally similar to the rest of the complement. Secondly, the $\mathrm{Y}$ chromosomes of $R$. acetosa undergo regular transcription (Clark, unpublished data, cited in Parker \& Clark, 1991; Parker, 1990), and are decondensed in premeiotic interphase (Zuk, 1969a). In accordance with its facultative heterochromatinization is the observation of Zuk (1969a, b, 1970a, b) that the two Ys are late replicating with respect to the $\mathrm{X}$ and the autosomes. The $\mathrm{Y}$ chromosomes are also essential for the differentiation of pollen mother cells and the progress of meiosis (Parker \& Clark, 1991).

The Y chromosomes of $R$. acetosa fluoresce positively after DAPI staining as do some heterochromatic C-bands (see Schweizer, 1976; John in Verma, 1988). They are also rich in the highly-repeated 180 bp DNA sequence reported here as are many heterochromatic $\mathrm{Y}$ chromosomes. It is possible then to consider these chromosomes as being a special kind of chromatin, a puzzling chromatin as it combines characteristics both of euchromatin and of heterochromatin. However, with respect to the association of heterochromatin and of highly repeated sequences it must be pointed out that it is not constant and unequivocal: cases of heterochromatic regions are known in which no satellite DNA is found while in other cases highly repeated sequences may be associated with euchromatic regions (Verma, 1988). The Y chromosomes of $R$. acetosa can then be of a euchromatic nature but enriched in highly repeated DNA sequences with a tandem organization in some regions. This structure could explain some of its cytogenetic characteristics. The existence of regions enriched in highly repeated sequences in these chromosomes could permit binding of proteins implicated in the facultative heterochromatinization and/or in the positive staining with DAPI.

With respect to the origin and evolution of the $\mathrm{Y}$ chromosome system of $R$. acetosa, our observations of the close similarity from both cytogenetic and mole-

The nature of the $\mathrm{Y}$ chromosomes is puzzling. These chromosomes are heteropycnotic like many sex 

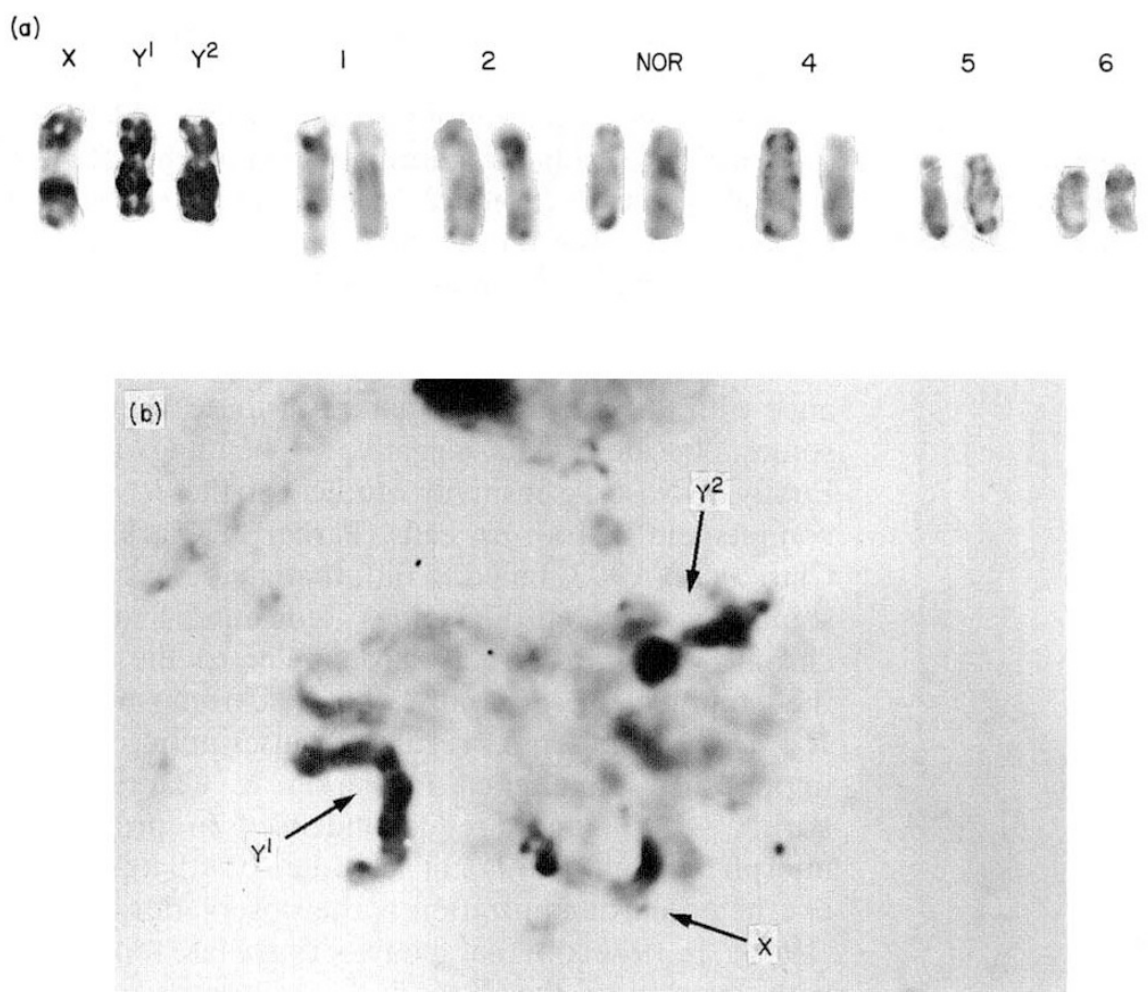

Fig. 4 Karyotype (a) and mitotic prophase (b) of a R. acetosa male after in situ hybridization with the $\mathrm{pRa} 37$ clone.

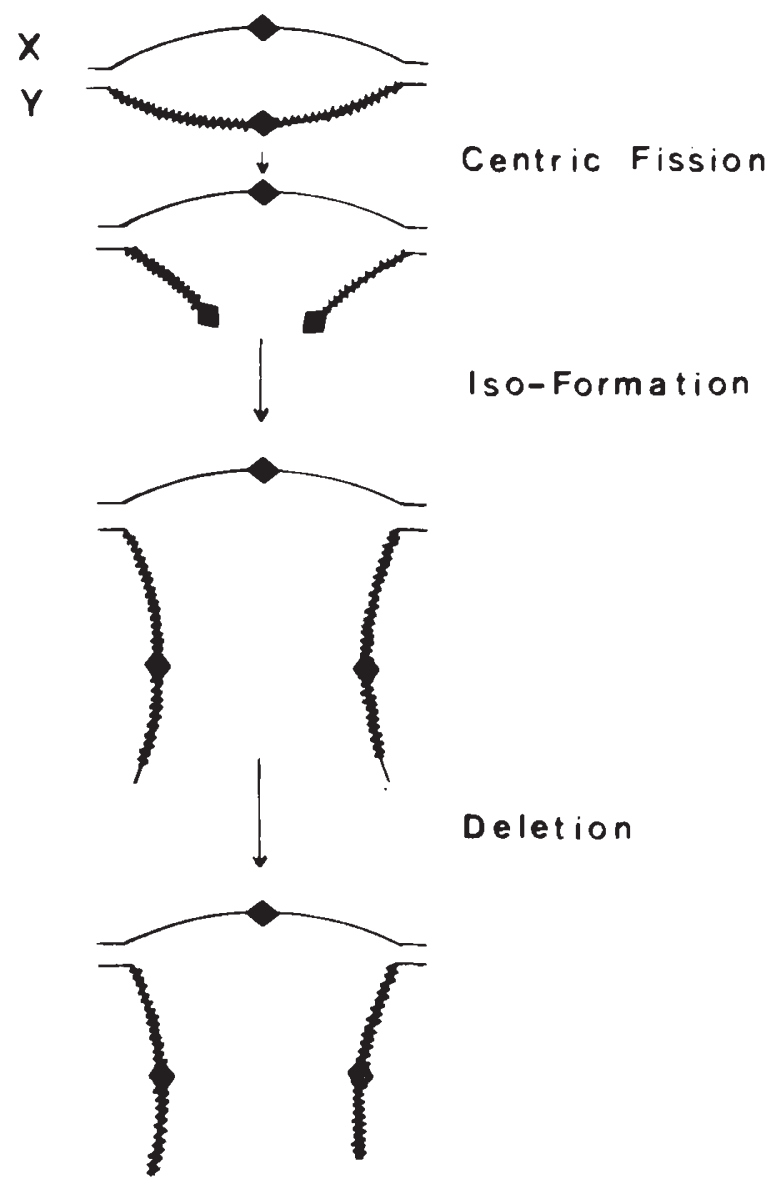

Fig. 5 Possible mode of origin of the multiple sex chromosome system of $R$. acetosa from a homomorphic parent. cular points of view between the $\mathrm{Y}$ chromosomes and between the Y-chromosomes and the $\mathrm{X}$ puts in doubt the hypothesis of an origin from a standard $\mathrm{XX} / \mathrm{XY}$ system by means of $\mathrm{X} /$ autosome translocation (Smith, 1972). If the multiple sex chromosome system of $R$. acetosa had originated by such a mechanism we would expect the more recently appearing $\mathrm{Y}$ chromosome to retain some homology with its former homologue, now a segment of the $\mathrm{X}$ chromosome. Thus the $\mathrm{Y}$ chromosomes would show some differences. In the wellanalysed case of the $\mathrm{X}^{1} \mathrm{X}^{2} / \mathrm{X}^{1} \mathrm{X}^{2} \mathrm{Y}$ of Drosophila miranda which originated by an interchange between an autosome and the $\mathrm{Y}$ chromosome of a standard $\mathrm{XX} / \mathrm{XY}$ system, the $\mathrm{X}^{2}$ and neo-Y retain some common features (Steinemann, 1982), and the neo-Y is incompletely heterochromatinized and degenerated (Steinemann \& Steinemann, 1991).

Our observations are more in accordance with a hypothesis in which the two $\mathrm{Y}$ chromosomes of $R$. acetosa originated as a consequence of duplication of a single chromosome (Wilby, 1987). This would involve several steps: (1) centric misdivision to produce two telocentrics, (2) isochromosome formation by both telocentrics, (3) restriction of pairing and chiasma formation to one telomeric region on each $\mathrm{Y}$ chromosome (Fig. 5). The Y chromosomes of the R. acetosa group still maintain their large size, being about 85 per cent and 75 per cent the length of the $X$ chromosome. The facultative heterochromatinization of the Ys may have been implicated in the control of $\mathrm{X} / \mathrm{Y}$ homology to 
facilitate consistent multiple formation and regular disjunction at anaphase I. This may thus explain the similarities between Ys and, to some extent, their puzzling cytogenetic characteristics. If the proto-Ys of $R$. acetosa have originated by $\mathrm{X}$ duplication, this precludes the progressive degeneration of the Y chromosomes (involving destruction of genetic information on the $\mathrm{Y}$ and conversion of a euchromatic to a heterochromatic chromosome) which, in the hypothesis of Muller $(1918,1932)$, normally occurs if the Y chromosome is in only one dose. In addition this hypothesis of the origin of the $\mathrm{Y}$ chromosomes of $R$. acetosa may also explain the essentially euchromatic nature of these chromosomes.

\section{References}

BLACKBURN, K. 1923. Sex chromosomes in plants. Nature, 112, 687-688.

CLARK, M. S., PARKER, J. S. AND AINSWORTH, C. C. 1993. Repeated DNA and heterochromatin structure in Rumex acetosa. Heredity, 70, 527-536.

DELlaporTA, s. L., WOOD, J. AND HICKS, J. B. 1983. A plant DNA minipreparation. Version II. Plant Mol. Biol. Rep., 1, 19-21.

DOBZHANSKY, т. 1935. Drosophila miranda, a new species. Genetics, 20, 377-391.

KIHARA, H. AND ONO, T. 1923. The sex-chromosomes of Rumex acetosa. Z. Indukt. Abst. U. Vererb., 39, 1-7.

MACKNIGHT, R. H. 1939. The sex-determining mechanism of Drosophila miranda. Genetics, 24, 180-201.

MARSHALL GRAVES, J. A. AND WATSON, J. M. 1991. Mammalian sex chromosomes: evolution of organisation and function. Chromosoma, 101, 63-68.

MULLER, H. J. 1918. Genetic variability, twin hybrids and constant hybrids, in a case of balanced lethal factors. Genetics, 3, 422-499.

MULLER, H. J. 1932. Some genetic aspects of sex. Am. Nat., 66, $118-138$.

NEGRUTIU, I. AND SALA, F. 1991. Sexual development in plants: an open question of strategic importance. Plant. Sci., 80, $1-6$.

oHNo, s. 1967. Sex Chromosomes and Sex-linked Genes. Springer, Berlin, Heidelberg.

PARKER, J. S. 1990. Sex chromosomes and sexual differentiation in flowering plants. Chromosomes Today, 10, 187-198.

PARKER, J. S. AND CLARK, M. S. 1991. Dosage sex chromosome systems in plants. Plant Sci., 80, 79-92.
SAMBROOK, J., FRITSCH, E. F., MANIATIS, T. 1989. Molecular Cloning, a Laboratory Guide, 2nd edn. Cold Spring Harbor Laboratory Press, New York.

SCHWARZACHER, T., AMBros, R. AND SCHWEIZER, D. 1980. Application of giemsa banding to orchid karyotype analysis. $\mathrm{Pl}$. Syst. Evol., 134, 293-297.

SCHWEIZER, D. 1976. Reverse fluorescent banding with chromomycin and DAPI. Chromosoma, 58, 307-324.

SCHWEIZER, D. 1980. Simultaneous fluorescent staining of R bands and specific heterochromatic regions (DA/DAPI bands) in human chromosomes. Cytogenet. Cell Genet., 27, 190-193.

SIMPSON, P. R., NEWMAN, M. A., DAVIES, D. R. 1988. Detection of legumin gene DNA sequences in pea by in situ hybridization. Chromosoma, 96, 454-458.

SMITH, B. W. 1972. Evolution of sex determining mechanisms in Rumex. Chromosomes Today, 2, 172-182.

STEInEmann, M. 1982. Multiple sex chromosomes in Drosophila miranda: a system to study the degeneration of a chromosome. Chromosoma, 86, 59-76.

STEINEMANN, M. AND STEINEMANN, S. 1991. Preferential Y chromosomal location of TRIM, a novel transposable element of Drosophila miranda, obscura group. Chromosoma, 101, 169-179.

VERMA, R. S. (ED.) 1988. Heterochromatin: Molecular and Structural Aspects. Cambridge University Press, New York.

WESTERGAARD, M. 1958. The mechanism of sex determination in dioecious flowering plants. Adv. Genet., 9, 217-281.

white, M. J. D. 1973. Animal Cytology and Evolution. Cambridge University Press, Cambridge.

wILBY, A. s. 1987. Population cytology of Rumex acetosa. Ph.D Thesis, University of London.

WILBY, A. S. AND PARKER, J. S. 1986. Continuous variation in the Y-chromosome structure of Rumex acetosa. Heredity, 57, 247-254.

WILBY, A. S. AND PARKER, J. S. 1988a. The supernumerary segment systems of Rumex acetosa. Heredity, $\mathbf{6 0}$, 109-117.

WILBY, A. S. AND PARKER, J. S. 1988b. Recurrent patterns of chromosome variation in a species group. Heredity, 61, 55-62.

ZUK, J. 1969a. Analysis of Y chromosome heterochromatin in Rumex thyrsiflorus. Chromosoma (Berl.), 27, 338-353.

ZUK, J. 1969b. Autoradiographic studies in Rumex with special reference to sex chromosomes. Chromosomes Today, 2, 183-187.

ZUK, J. 1970a. Function of Y-chromosomes in Rumex thyrsiflorus. Theor. Appl. Genet., 40, 124-129.

ZUK, J. 1970 b. Structure and function of sex chromosomes in Rumex thyrsiflorus. Acta Soc. Bot. Pol., 39, 539-564. 